\title{
O DISCURSO POÉTICO E AS RELAÇÕES DE E COM O PODER NA POESIA DE CACASO
}

\section{POETIC DISCOURSE AND THE POWER RELATIONS AND RELATIONS WITH THE POWER IN THE POETRY BY CACASO}

\author{
Guaraciaba Micheletti* \\ Universidade Cruzeiro do Sul, São Paulo, SP, Brasil \\ Universidade de São Paulo, São Paulo, SP, Brasil
}

\begin{abstract}
Resumo: A literatura, como toda expressão arrística, estabelece relaçõoes com o contexto histórico. Dependendo do autor, das circunstâncias polfitico-sociais e mesmo das tendências estéticas, encontrar-se-ão marcas mais vincadas no discurso literánio. Medeiros (http://www.portalconscienciapolitica.com.br/products/iteratura-engajada/, referindo-se a Sartre, registra que "há escritores que escolhem "engajar-se" através de suas obras e escritos a partir dos quais expressam, entre outras coisas, o embate entre a arte e o realismo politico". É o que se constata na poesia de Cacaso. Estabelecendo um claro diálogo com outros autores e valendo-se do recurso da ironia, Cacaso constrói uma poesia cerebrina e assaz críica à ditadura militar a que estava submetido o Brasil entre 1964 e o ińíco dos anos 80.0 engajamento implica numa reflexão do escritor sobre as relaçóes que trava a literatura com a politica e com a sociedade. Ainda, conforme Medeiros, "há um compromisso do escritor com a sociedade". Sem arvorara-se em panfletária, é esse o legado poético de Cacaso à Literatura Brasileria: uma poesia reflexiva, construída com o cotidiano, perpassada por toques de humor. Buscamos andisar as relaçõoes entre o poder e a construção poética de Cacaso, em poemas da coletânea "Lero-Lero", tendo como bases teóricas, entre outros, Bakhtin, Brait, Marrins.
\end{abstract}

Palavras-chave: Cacaso; Poesia brasileira; Estilistica.

\begin{abstract}
Literature, as every artisitic expression, establishes relations with the historical context. Depending on the author, the socio-political circumstances and even the aesthetic tendencies, there will be more pronounced marks in the literany discourse. Medeiros (http://www. portalconscienciapolitica.com.br/products /ilteratura-engajada/), referring to Sartre, states that "there are writers who choose to "engage" by means of their works and writings in which express, among other things, the dash between art and political realism." This is what can be observed Cacaso's poems. Establishing a dear dialogue with other authors and, using irony as a resource, Cacaso builds a imaginative and very critical poetty against the military dictatorship to which Brazil was subjected from 1964 to the beginning of the 1980's. The engagement implies in a writer's reflection upon the relations that restrains / impedes/ hampers literature with politics and the society. Also, according to Medeiros, there is a commitment between the author and the society: " Without being a pamphleteer, this is Cacaso's poetic legacy to the Brazilian Literature: a reflexive poetry, based on everyday life, marked by touches of humor. The present paper aims to analyze the relations between power and Cacaso's poetic construction, in poems from the "Lero-Lero" collection having Bakhtin, Brait, Martins and Van Dilk, among others, as theoretical basis
\end{abstract}

Keywords: Cacaso; Brazilian poetry; Stylistic.

* Professora Doutora da Universidade Cruzeiro do Sul - UNICSUL; professora aposentada da Universidade de São Paulo, São Paulo, SP, Brasil; guatti@uol.com.br 
Linha D'Água (Online), São Paulo, v. 30, n. 1, p. 145-158, jun. 2017

\section{Introdução}

Como indica o título, este artigo focaliza as relações entre o poder e a construção poética de Cacaso, em poemas da coletânea Lero-Lero, em especial os que se encontram em Grupo Escolar. As bases teóricas estão na Estilística, em particular num viés de uma estilística discursivo-textual, na qual se valorizam além dos tradicionais aspectos do enunciado, elementos da enunciação. Para uma análise mais minuciosa, combinamos elementos de algumas outras teorias como da Análise do Discurso em suas várias correntes e da Linguística Textual, ressaltando que elas não se sobrepõem, mas dialogam. Algumas observações prendem-se, também, a questões focalizadas pela Teoria Literária. Esse rol de teorias pode parecer tratarse de uma miscelânea, mas o fato é que certas abordagens se voltam aqui e ali para aspectos que, com os avanços dos estudos da linguagem, ficaram delimitados por alguns campos investigativos; assim, para uma abordagem mais abrangente, tornase necessária uma aproximação com diferentes estudos.

De acordo com a vertente bakhtiniana, o homem constitui-se no discurso, espaço em que pode posicionar-se e interagir socialmente. A escolha do tema, do gênero e, sobretudo, das palavras que irão compor a sua fala não está incólume à subjetividade e parcialidade, deixando, portanto, suas palavras evidenciar uma visão de mundo.

Segundo Bakhtin, são os julgamentos de valor que determinam a seleção das palavras feitas pelo falante e a recepção dessa seleção (a co-seleção) feita pelo ouvinte. E esclarece que o falante seleciona as palavras não no dicionário, mas no contexto de vida onde as palavras foram embebidas e se impregnaram de julgamentos de valor. (BRAIT, 2003, p. 21)

Van Dijk (2003, p. 21), da Análise Crítica do Discurso, afirma que ideologias podem ser manifestadas em todas as estruturas da linguagem escrita ou oral, mas são mais comuns em umas que em outras. No léxico, por exemplo, as palavras, a depender do contexto, carregam um valor ideológico ou outro. A palavra ordem pode ter uma conotação na fala de uma pessoa de esquerda e outra na de uma pessoa de direita. De acordo com Barbosa (1981, p. 157), nós nos utilizamos do léxico 
para "entender o mundo, examiná-lo, "vê-lo", comunicar, efetuar a transmissão, recepção, armazenagem e recuperação da informação", isto é, compreendemos e retratamos o mundo por meio da linguagem. O recorte que fazemos deixa transparecer nossas ideologias.

Os temas, segundo Van Dijk (2003, p. 58), também contribuem para o estabelecimento do sentido do discurso: "El significado del discurso no se limita al significado de las palabras y las frases. El discurso también cuenta con significados más "globales" como los "temas". Los temas representan la información más importante del discurso y explican de qué trata éste en general". $\mathrm{O}$ assunto tratado permite que o enunciador selecione palavras que pertençam ao mesmo universo semântico, a fim de reforçar seu posicionamento. De acordo com os estudos semânticos de Ullmann (1964, p. 501):

Como pode ver-se, o "campo associativo" de uma palavra é formado por uma intrincada rede de associações, baseadas algumas na semelhança, outras na contiguidade, surgindo umas entre sentidos, outras entre nomes, outras ainda entre ambos. O campo é por definição aberto, e algumas das associações estão condenadas a ser subjetivas, embora as mais centrais sejam em larga medida as mesmas para a maioria dos locutores.

Este trabalho volta-se para o discurso literário, em que um sujeito lírico expõe de modo singular suas visões de mundo. Queremos observar, entre outros aspectos, como o poeta seleciona as palavras, a que campos semânticos pertencem, a fim de expressar sua percepção do mundo, seja no que tange à sua opção ideológica ou no que diz respeito aos seus sentimentos.

A literatura, como toda expressão artística, estabelece relações com o contexto histórico. Dependendo do autor, das circunstâncias político-sociais e mesmo das tendências estéticas, encontrar-se-ão marcas mais vincadas no discurso literário. Medeiros ${ }^{1}$, referindo-se a Sartre, registra que "há escritores que escolhem "engajar-se" através de suas obras e escritos a partir dos quais expressam, entre outras

1 Disponível em: http://www.portalconscienciapolitica.com.br/products/literatura-engajada/. Acesso em: 27 mai. 2016. 
coisas, o embate entre a arte e o realismo político". É o que se constata na poesia de Cacaso, Antonio Carlos Brito (1944-1987).

Estabelecendo um claro diálogo com outros autores e valendo-se do recurso da ironia, Cacaso, um dos ícones da poesia marginal dos anos 70, constrói uma poesia cerebrina e assaz crítica em relação à ditadura militar a que estava submetido o Brasil entre 1964 e o início dos anos 80. Seria a poesia de Cacaso uma poesia engajada? É a primeira pergunta que se pode colocar. O engajamento implica uma reflexão do escritor sobre as relações que trava a literatura com a política e com a sociedade em geral. Nela, ainda conforme Medeiros, há uma percepção "que a sensibilidade estética pode se tornar um instrumento que convida o leitor a se entregar a um mundo de reflexões e pensamentos sobre os principais problemas da sociedade: o mundo das guerras, da luta das minorias, das desigualdades sociais etc. Há, por assim dizer, um compromisso do escritor com a sociedade. Mesmo sendo uma postura artística das mais legítimas, o fato de alguns autores terem se debruçado em questões histórico-ideológicas com, por vezes, vieses partidários, transformou o termo literatura engajada em algo bastante pejorativo. Quase sempre quando se atribui essa característica a um autor, fica estabelecido que a qualidade artística de sua obra foi relegada a um segundo plano, que ela é um instrumento de proselitismo.

Assim, é preciso registrar desde logo que, sem arvorar-se em panfletária, o engajamento é uma das marcas da poesia de Cacaso. Uma poesia reflexiva, construída com o cotidiano, perpassada por toques de humor. Nele, é notória uma preocupação com o fazer poético, com uma reflexão sobre a literatura, mas ela não está infensa às condições histórico-sociais que se veem retratadas na poesia. Cacaso vive numa época de transformações sociais em que o mundo ocidental coloca em xeque valores éticos e morais, e mais, num regime político ditatorial em seu país.

\section{Lero Lero: relações entre a poesia e o poder}

Em Lero Lero, o que mais espelha essa condição é Grupo Escolar, livro publicado numa primeira edição em 1974. Foi organizado em quatro partes, denominadas lições, a saber: 1ª lição: “Os extrumentos técnicos”; 2a lição: "Rachados e perdidos”; 
Linha D'Água (Online), São Paulo, v. 30, n. 1, p. 145-158, jun. 2017

3a . lição: "Dever de caça"; 4a lição: "A vida passada a limbo". Todas as "lições" têm seus títulos cunhados em jogos com expressões bastante usuais nas quais se troca um dos elementos do sintagma por outro que rompe com a expressão cristalizada e instaura a ironia que perpassa todos os poemas que constituem esse livro.

O primeiro bloco - "Os extrumentos técnicos" - que se inicia por "Cartilha" apresenta um teor mais marcadamente metalinguístico, trazendo uma discussão sobre a poesia e o seu fazer. O poema é composto por cinco estrofes, identificadas pelas vogais: a, e, i, o, u, nas quais o enunciador expressa sua busca, com destaque para o segmento abaixo:

$\mathrm{e}$

Não quero os sóis que praticam as mil fotos do objeto, a noite sempre nascendo da noite em revelação.

Preciso da palavra que me vista não da memória do susto mas da véspera do trapezista.

(BRITO, 2012, p. 144)

Declara-se, no quarto verso da estrofe ("preciso"), a necessidade de uma verbalização poética que será praticada nos poemas das quatro lições: é um aprendizado que remete à reflexão de João Cabral de Mello Neto sobre a pedra, na composição "Educação pela pedra”, pois o enunciador afirma nos versos finais:

$\mathrm{u}$

Quero meu poema apenas pedra:

ou seu fantasma emergindo

por dentros e foras.

(BRITO, 2012, p. 145)

É na segunda e terceira "lições", já de posse dos instrumentos ("extrumentos técnicos") que predominam as relações da poesia com o poder. Os jogos com 
Linha D'Água (Online), São Paulo, v. 30, n. 1, p. 145-158, jun. 2017

formas cristalizadas da linguagem, com os quais se instaura a relação com o poder se desvelam: há "rachados e perdidos" e "dever de caça". Na segunda lição está "Aquarela", um dos quadros mais impactantes, apresentado por Soares (2009, p. 471-472) como a "descrição alegórica de uma cena de tortura. $\mathrm{O}$ substantivo "cavalete", mantida a ambiguidade, remete ao instrumento de tortura, mas também faz alusão ao tripé utilizado para apoiar a tela. A pintura, porém, far-se-á com tintas diferentes. O "corpo" definido como "pássaro que agoniza” é um corpo moribundo, torturado."

Aquarela
O corpo no cavalete
é um pássaro que agoniza
exausto do próprio grito.
As vísceras vasculhadas
principiam a contagem
regressiva.
No assoalho o sangue
se decompõe em matizes
que a brisa beija e balança:
o verde - de nossas matas
o amarelo - de nosso ouro
o azul - de nosso céu
o branco o negro o negro
(BRITO, 2012, p. 151)

O intertexto e a interdiscursividade que se faz com "Aquarela do Brasil" de Ari Barroso agudiza um sentimento agônico que se transmite ao enunciatário/ leitor, pois os matizes da agonia são apresentados com as cores que representam um sentimento ufanista exalado pela canção. Esse registro buscado na memória, memória a que Cacaso se refere textualmente com frequência em suas composições, pode ser considerado também um índice de ironia.

$\mathrm{Na}$ terceira lição, prosseguem as reflexões e como assinalou Soares em relação ao poema "O futuro já chegou", diversamente do anterior, alegórico, este como 
Linha D'Água (Online), São Paulo, v. 30, n. 1, p. 145-158, jun. 2017

muitos outros se constrói referencialmente (2009, p. 470). Nele não há uma crítica à ditadura militar, mas ao sistema capitalista:

Logias e analogias

No Brasil a medicina vai bem

mas o doente ainda vai mal.

Qual o segredo profundo

desta ciência original?

É banal: certamente

não é o paciente

que acumula capital.

(BRITO, 2012, p. 155)

Transformando “-logia”, um elemento da língua portuguesa de formação de palavras que pode significar algo relativo à arte e ou à ciência, em um substantivo de composição do título, juntando à analogia (Cf. Houaiss eletrônico) ${ }^{2}$ que trata de relação entre pares de conceitos dessemelhantes, o enunciador se coloca numa atitude irônica: No Brasil a medicina vai bem / mas o doente vai mal. Assim, em um discurso estruturado de modo prosaico, a segmentação em versos com acoplamentos e a utilização de rimas externas e internas, bem como a frase interrogativa acentua essa posição irônica. A interrogação é respondida nos versos subsequentes em que "banal", "original" rimam com "capital" e o poema se conclui, deixando ao leitor uma reflexão sobre "não é o paciente / que acumula capital.

A quarta lição vem com “A vida passada a limbo". Nela, expressam-se as relações amorosas, como uma espécie de busca para o passar-se a limpo, mas a violência predominante nas duas lições anteriores, fica vincada nas diversas composições como em "Logia e Mitologia", comentada anteriormente e nos fragmentos abaixo:

Meu coração

sabe que há morcegos de pesadas olheiras

que há cabras malignas que há

2 Cf. http://houaiss.uol.com.br/-logia;/analogia.h 
Linha D'Água (Online), São Paulo, v. 30, n. 1, p. 145-158, jun. 2017

cardumes de hienas infiltradas

no vão da unha na alma

a vida anoitece provisória

centuriões sentinelas

do Oiapoque ao Chuí

(BRITO, 2012, p. 163)

e no poema que encerra o bloco e o livro: "Grupo escolar":

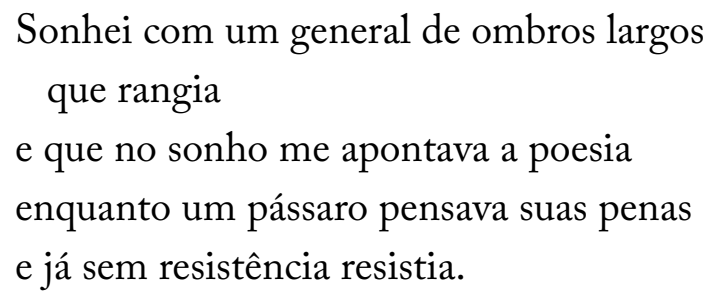

(BRITO, 2012, p. 168)

Ou seja, a poesia não fica passada a limpo, mas a limbo, palavra que, entre as muitas acepções possíveis, pode indicar um "estado de indecisão, incerteza, indefinição" ou mesmo "ausência de memória, olvido, esquecimento", ou ainda um "depósito de coisas inúteis" (Cf. Houaiss eletrônico) ${ }^{3}$ Pode-se, em decorrência, inferir que a poesia ou o ato de fazê-la seja inútil, que se vive, nela, incertezas, nada definido.

Pelo lado da poesia, há uma busca por uma expressão que possa dar conta esteticamente de uma experiência histórica, de algo que está sendo vivenciado e que, possa ser, registrado, uma espécie de combate a uma situação-limite em que o poeta / enunciador se encontra aprisionado. Como já nos referimos, os subtítulos do livro nascem de um processo de desconstrução de expressões cristalizadas pelo uso e por uma substituição de elementos que rompem com o senso comum e aduzem um certo humor, uma pitada de ironia que vinca toda a produção.

Isso também ocorre nos poemas, o dito popular "as aparências enganam" transforma-se num título que inverte a proposição: "As aparências revelam", poema que se vale de trocadilhos: Afirma / Firma/confirma em que aparecem dois importantes

3 Cf. http://houaiss.uol.com.br/busca?.palavra+limbo 
Linha D'Água (Online), São Paulo, v. 30, n. 1, p. 145-158, jun. 2017

produtos nacionais: café e aço, mas que entram num jogo de ambiguidade inicial (primeira estrofe) que evolui para a "violência", aliás expressão recorrente. $\mathrm{O}$ aço, metal, metonimicamente se relaciona à ditadura a que está submetido o país

Afirma uma Firma que o Brasil

confirma: "Vamos substituir o

Café pelo Aço”.

Vai ser duríssimo descondicionar

o paladar.

Não há na violência

que a linguagem imita

algo de violência

propriamente dita?

(BRITO, 2012, p. 156)

A questão econômica se associa ao momento político e serve de mote para o poeta. Traduzindo, pode-se dizer que, na primeira estrofe, uma empresa - Firma - (mas quem é ela?) promoverá uma substituição uma vez que os verbos remetem a uma postura assertiva pela sua significação e pela sua forma, presente do indicativo. $\mathrm{Na}$ segunda, tem-se o salto: café se relaciona ao paladar; aço, não. Nela surge o contexto político social que será evidenciado na estrofe final por meio da frase interrogativa que a constitui. Ainda é de se notar a presença das rimas que tanto na segunda como na terceira estrofes ficam reverberando num claro apelo ao enunciatário-leitor.

Segue-se "Reflexo condicionado" no qual novamente surge como título uma expressão do cotidiano, não desconstruída em si mesma, mas questionada nos poucos versos que compõem o poema:

\section{REFLEXO CONDICIONADO}

pense rápido:

Produto Interno Bruto

ou 
Linha D'Água (Online), São Paulo, v. 30, n. 1, p. 145-158, jun. 2017

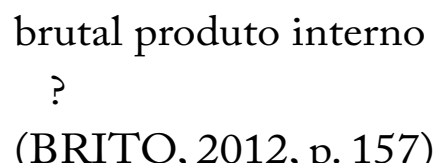

Nesse poema, o único verbo encontra-se no primeiro verso - pense rápido: no qual o enunciador dirige-se ao enunciatário no modo imperativo; joga com o conhecido PIB - Produto Interno Bruto - para questionar uma postura aparentemente econômica ao levantar as consequências sociais desse "reflexo condicionado" a que estão aprisionados os economistas com suas regras econômicas. $\mathrm{O}$ enunciador procede a uma inversão dos termos e a uma ligeira mudança no adjetivo Bruto => brutal, de certo modo lançando ao leitor uma espécie de desafio que se conclui no ponto de interrogação, único elemento do verso final.

No poema que se segue, pela disposição tipográfica e pelo uso de caixa alta para títulos, pode-se considerar o título mais longo que o poema propriamente dito, tem-se nele uma contextualização histórica e geográfica. Como em outros poemas, mas mais particularmente neste, a ironia pode ser um modo estruturante e como tal propõe uma reflexão. Conforme salienta Beth Brait, categorias como citação, menção eco e coesão aparecem como elementos essenciais à ironia articulada com a intertextualidade e a interdiscursividade" (1996, p. 57). E essa articulação se manifesta de modo pleno no poema que passamos a considerar:

\title{
PRÉ-HISTÓRIA CONTEMPORÂNEA PERIFÉRICA OU NINGUÉM SEGURA ESSA AMÉRICA LATINA OU OS IMPOSSÍVEIS HISTÓRICOS OU A OUTRA MARGEM DO IPIRANGA
}

\author{
Jamais mudar pela violência \\ masmanter pela violência: \\ morte ou dependência \\ (BRITO, 2012, p. 157)
}

O título apresenta-se como disposto em versos e há uma profusão de uso do conectivo ou, aparentemente, com objetivo excludente, mas que se revela aditivo, ou seja, trata-se 1) paradoxalmente de pré-história contemporânea periférica; 2) 
Linha D'Água (Online), São Paulo, v. 30, n. 1, p. 145-158, jun. 2017

por outro lado "ninguém segura essa América Latina"; 3) que contém ou apresenta "os impossíveis históricos", fatos inacreditáveis; 4) por fim, em "a outra margem do Ipiranga" insere-se o Brasil. Brasil que não se situa nas "margens plácidas", ${ }^{4}$ onde se ouviu "o brado retumbante", e sem a moldura do "sol da liberdade, pois encontrase à "outra margem".

Os três versos que compõem o corpo do poema retomam o recorrente tema da violência (na obra em análise) que neles rima com dependência, invertendo a proposição do Hino Nacional. A mudança da condição de colônia para país independente se fez sem violência, às "margens plácidas", possivelmente referência, ainda, à forma pela qual os militares tomaram o poder: "Jamais mudar pela violência", mas como permaneceram nele por cerca de 20 anos: "mas manter pela violência". Os dois verbos: mudar e manter, que, semanticamente, constituem os pilares do poema encontram-se no modo infinitivo, ou seja, com um valor não marcado temporalmente o que implica uma duração não delimitada. O verso final subverte a frase atribuída a D. Pedro I, às margens do Ipiranga: "Independência ou morte" que numa alusão à situação da ditadura militar transforma-se em "morte ou dependência", figurando uma situação sem saída.

Como a maioria dos poemas das lições 2 e 3 , o enunciador não se apresenta diretamente em seu discurso, buscando descrever situações e fazer com que, por meio delas, o enunciatário, seu leitor reflita sobre o status quo. Por vezes, vale-se do imperativo ou da interrogação para comunicar-se, mas o pronome eu e os dêiticos de primeira pessoa são bastante escassos.

$\mathrm{Na}$ 4a. Lição, em todos os poemas o eu se faz presente, é um segmento da obra dedicado às relações amorosas e familiares, mas o leitor de Cacaso não se defrontará com uma tradicional lírica amorosa. Os poemas são plenos de referências e ou imagens que remetem à situação política. Abrindo "A vida passada a limbo", tem-se o poema "Cinema mudo", de intenso lirismo amoroso em que /Um telegrama urgente/ anuncia a bem-amada/ se subdivide em quatro segmentos. No III,

4 Hino Nacional Brasileiro. Letra de Joaquim Osório Duque Estrada Seguem-se as duas estrofes iniciais: Ouviram do lpiranga as margens plácidas / De um povo heroico o brado retumbante, / E o sol da liberdade, em raios fúlgidos, /Brilhou no céu da pátria nesse instante. // Se o penhor dessa igualdade. Conseguimos conquistar com braço forte /, em teu seio, ó liberdade, / Desafia o nosso peito a própria morte! 
Linha D'Água (Online), São Paulo, v. 30, n. 1, p. 145-158, jun. 2017

em meio a expressão de sentimentos em relação à amada, o enunciador se vale de imagens inusitadas e contundentes:

\author{
III \\ Vejo seu retrato como se eu \\ já tivesse morrido. \\ Grinaldas batem continência. \\ Livre na sua memória escolho a forma \\ que mais me convém: querubim \\ gaivotas blindadas \\ suave o tempo suspende a engrenagem. \\ Do outro lado do jardim já degusto \\ os inocentes grãos da demência. \\ (BRITO, 2012, p. 161)
}

Dentre essas imagens, duas desvelam a influência do momento político: "Grinaldas que batem continências" e a presença de "gaivotas blindadas". Nessas expressões, é notória uma duplicidade: beleza (grinaldas), liberdade (gaivotas), frequentes atributos da poesia lírica, versus as marcas militares e, mais especificamente da ditadura militar que o enunciador traz para suas composições. São imagens que Martins identifica como "metáfora contemporânea, irracional, em que há semelhança emocional, os termos (são) aproximados despertando um sentimento semelhante" (MARTINS, 2008, p. 24).

\title{
Considerações finais
}

Por fim, cabe assinalar que a memória, especialmente aquela que se relaciona à literatura e à cultura de modo mais geral figura como um dos elementos básicos da poesia de Cacaso, seja no que diz respeito a citações ou mesmo no aproveitamento de expressões cristalizadas que, ironicamente, são reinterpretadas pelo poeta.

Em todo o processo de enunciação, se faz presente a preocupação com um dizer, numa busca por uma forma: lembrando o livro se inicia com o poema "Cartilha”, referências a um périplo (BRITO, 2012, p. 146), uma composição 
Linha D'Água (Online), São Paulo, v. 30, n. 1, p. 145-158, jun. 2017

cujo título é protopoema, na qual o enunciador afirma: "tateio esta caverna" (BRITO, 2012, p. 147). A vida vivida surge com mais força a partir da 2a. Lição, numa tentativa de denúncia e de procura de respostas para a situação de aprisionamento pela ditadura militar.

Voltemos ao título desta comunicação: "O discurso poético e as relações de e com o poder na poesia de Cacaso". Nos poemas, o poder se manifesta como algo que se presentifica por referências, na maioria das vezes indireta, e atormenta o enunciador. São imagens, metáforas que traduzem o militarismo e as suas consequências, e um léxico que remete à violência. Há, ainda, poemas em que a temática é o capitalismo selvagem. É o poder de dominação, de vida e morte sobre os cidadãos, tanto político, quanto econômico. Por outro lado, esse discurso poético se nutre do poder e estabelece com ele, por meio de uma atitude irônica, um jogo que também pode ser considerado como o poder da poesia que, com a palavra, denuncia a situação político-social.

\section{Referências}

BARBOSA, Maria Aparecida. Léxico, produção e criatividade: processos dos neologismos. São Paulo: Global, 1981.

BRAIT, Beth. As vozes bakhtinianas e o diálogo inconcluso. In: BARROS, Diana Luz Pessoa de; FIORIN, José Luiz. Dialogismo, Polifonia e Intertextualidade. São Paulo: Edusp, 2003. . Ironia em perspectiva polifônica. Campinas, São Paulo: Editora da UNICAMP, 1996.

BRITO, Antônio Carlos de. Lero-Lero (1967-1985). São Paulo: Cosac Naify, 2012.

FIORIN, José Luiz. Dialogismo, Polifonia e Intertextualidade. São Paulo: EDUSP, 2003.

MARTINS, Nilce Sant'Anna. Introdução à Estilística. 4.ed. rev. São Paulo: EDUSP, 2008.

MEDEIROS, Alexsandro Melo. Literatura Engajada. Disponível em: http://www.portalconscienciapolitica.com.br/ products/literatura-engajada/. Acesso em: 27 mai. 2016. 
Linha D'Água (Online), São Paulo, v. 30, n. 1, p. 145-158, jun. 2017

SOARES, Débora Racy. A poesia passada a limbo (reflexões sobre grupo escolar de Cacaso) In: Estudos de Sociologia, Araraquara, v.14, n.27, p. 465-476, 2009. Disponível em: http://seer.fclar. unesp.br/estudos/article/view/1949/1587. Acesso em 27 mai.2016.

ULLMANN, Stephen. Semântica: uma introdução à ciência do significado. 3.ed. Lisboa: Fundação Calouste Gulbenkian, 1964.

VAN DIJK, Teun A. Ideología y discurso. Barcelona: Ariel, 2003.

. La multidisciplinariedad del análisis crítico del discurso: um alegato em favor

de la diversidad. In: WODAK, Ruth; MEYER, Michael. (comp.). Métodos del análisis crítico del discurso. Barcelona: Gedisa, 2003. p. 143-177. Disponível em: http://www.discursos.org/oldarticles/La\%20multidisciplinariedad.pdf. Acesso em: 16 mai. 2016.

Recebido em 15/03/2017.

Aprovado em 29/07/2017. 